\title{
Artigos
}

\section{O processo civilizatório pela infância e o direito de brincar na educação infantil: algumas reflexões}

Resumo: O furto das práticas lúdicas e a disciplinarização por meio do corpo, em muitas instituições de Educação infantil, são mais do que ações esporádicas - elas transformamse em algo que se situa dentro da normalidade. Este artigo assume como objetivos principais: promover uma discussão e reflexão sobre a disciplinarização da infância por meio do controle das crianças, seja pela distribuição espacial, pela conduta dos professores ou, ainda, pela persistência de paradigmas históricos que insistem em afirmar que a presença do lúdico trabalha na contramão da aprendizagem e do desenvolvimento infantil. Ainda, busca alertar e defender a importância do lúdico na formação das crianças, refutando pressões, principalmente externas às instituições de Educação Infantil, que o secundarizam. Pauta-se na concepção de crianças como sujeitos de direitos - entre eles, o de brincar, assegurado por muitos documentos legais que visam à proteção da infância. No entanto, é preciso destacar que muitas instituições de Educação Infantil, pressionadas pela lógica neoliberal de políticas nacionais e internacionais, estão mais preocupadas com a preparação de obra do que com os direitos das crianças. Neste sentido, torna-se necessário que todos que atuam diretamente com as crianças não abram mão do acesso à atividade lúdica, visto que se trata de um direito da criança que precisa ser garantido no contexto da Educação Infantil.

Palavras-chave: Educação. Infância. Ludicidade. Jogo. Brincadeira.

\section{The civilization process for childhood and the right to play in children's education: some reflections}

Abstract: The theft of playful practices and disciplining through the body in many institutions of early childhood education are more than sporadic actions - they become something that is within normalcy. The main objectives of this article are: to promote a discussion and reflection on the disciplinarization of childhood through the control of children, either by spatial distribution, by teachers' behavior or by the persistence of historical paradigms that insist that the presence of play against learning and child development. Also, it seeks to alert and defend the importance of the playful in the training of children, refuting pressures, mainly external to the institutions of Early Childhood Education, which secondarily. It is based on the conception of children as subjects of rights - among them, the one of playing, secured by many legal documents that aim at the protection of the childhood. However, it should be noted that many institutions of early childhood education, which are under pressure from the neoliberal logic of national and international policies, are more concerned with the preparation of work than with the rights of children. In this sense, it is necessary that all who act directly with the children do not give up access to the play activity, since it is a child's right that needs to be guaranteed in the context of Early Childhood Education.

Keywords: Education. Childhood. Playful. Game. Just kidding.

\footnotetext{
' Doutora e Mestre em Educação pelo Programa de Pós-graduação em Educação da "Universidade Estadual Paulista" - UNESP Presidente Prudente/SP. É docente do Curso de Licenciatura em Pedagogia da Universidade do Oeste Paulista - UNOESTE em Presidente Prudente/SP. E-mail: nairazevedo@hotmail.com

2 Doutor em Educação pela Faculdade de Filosofia e Ciências - UNESP de Marília. Docente no Departamento de Pós-graduação em Educação Mestrado/Doutorado em Educação da "Faculdade de Ciências e Tecnologia" - FCT/Unesp, Campus de Presidente Prudente. E-mail: miltonlima@fct.unesp.br
} 
"Dona Cleópatra, que tomava conta do portão, já estava de cara feíssima, que pra ela, chegar atrasado na escola era pior que bater na mãe...

- Já pra dentro, crianças. Joguem fora o chiclé, onde é que já se viu? Ó Tábata, você está cansada de saber que não pode entrar de fita vermelha na cabeça. E nada de risadinhas no corredor que atrapalha as outras classes, nada disso, nada daquilo, não pode, não pode!

As crianças correram para a classe, bateram na porta e entraram, muito ressabiadas... A professora também já estava na lição do "Não Pode".

- Não pode escrever no caderno com a caneta vermelha. Esta é só pros títulos. E não pode sentar de lado que é pra não atrapalhar os vizinhos. E não pode olhar pro lado, nem pra trás, e nem dar risadinhas, nem pode ficar mostrando figurinhas, esta porcaria de álbum, exploração de multinacional, vamos acabar com isso, e vamos acabar com essas conversas de programas de TV, é por isso que o Brasil não vai pra frente, crianças, não verão país como esse.".

(Ruth Rocha - A menina que aprendeu a voar)

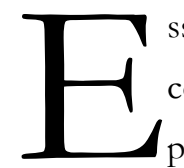

ssa epígrafe introdutória, apesar de se tratar de uma história fictícia, pode perfeitamente ser confundida com a vida real de muitas instituições de Educação Infantil - não é difícil percebermos cenas parecidas com a descrita pela "menina que aprendeu a voar", e destacamos isso baseando-nos em experiências próprias de nosso cotidiano como docentes e pesquisadores. O furto das práticas lúdicas, a imobilidade, a disciplinarização por meio do corpo em muitos contextos educacionais tornaram-se uma rotina.

Uma questão central, nesse caso, busca compreender como, quando e por que tais práticas pedagógicas que reprimem a ludicidade nesses espaços, já a partir da Educação Infantil, ganharam força. Neste sentido, buscamos refletir como isso foi construído ao longo de décadas de educação pública no Brasil. O que queremos inferir, baseando-nos em vários estudos, é que ações repressoras do lúdico, infelizmente bastante comuns em muitas instituições educacionais, são resultados de imposições históricas às crianças.

Freire (1991) nos faz refletir sobre a criança que recebemos todos os dias na Educação Infantil. Pensar na criança como um ser "ideal" e não "real" faz parte de nossa rotina, pois tentamos padronizá-la por meio de concepções nas quais precisa se encaixar para ter "bom" ou "mau" desempenho ou, quando tentamos fazê-la adotar padrões comportamentais, sociais, afetivos ou mesmo tentamos discipliná-la corporalmente por meio da imobilidade, tão exigida em muitas instituições de Educação Infantil.

Tenho verificado que, quando tratamos com seres humanos, procuramos tratar com seres ideais e não exatamente com seres reais. Nós idealizamos as pessoas, as coisas, o mundo, que é como queremos que sejam, o que dá a exata medida do nosso fracasso em nossas intervenções - um dos resultados da simplificação do complexo. (FREIRE, 1991, p. 71).

Tentamos, também, construir a criança "ideal" quando nós, adultos já "experientes", colocamos nossas expectativas futuras em nossos alunos, filhos, sobrinhos ou netos, por exemplo. Quem nunca se pegou imaginando e até fazendo planos futuros para a vida profissional daquele pequeno ser que, gerado direta ou 
indiretamente por nós, pensamos ser "nosso" e, portanto, sabemos o que pode ser melhor para ele. Não há nada de mal em desejar o bem aos nossos herdeiros, afinal qual pai ou mãe (e podemos também dizer tios, avós, etc.) que, estando seu descendente com fome lhe daria para comer uma pedra? Nós, adultos, na maioria das vezes estamos sempre querendo acertar, embora essa intenção não seja sempre garantia de sucesso.

Estando a criança na instituição de Educação Infantil, na família, na igreja, na sociedade em geral, muitas vezes não lhe resta alternativa a não ser fazer aquilo que lhe determinaram ou, ser aquele a quem projetaram que um dia fosse - um vir a ser, o futuro da nação, o amanhã do mundo. Larrosa (2010) afirma que a alteridade da infância nos desafia a todo instante e sempre estamos trabalhando para reduzir o que ainda resta de desconhecido nela, buscando uma subversão ao que ainda é selvagem e indomável em sua forma de ser. Então, adotamos o posicionamento de que a infância "já foi explicada por nossos saberes, submetidas por nossas práticas e capturadas por nossas instituições" (LARROSA, 2010, p. 185).

À criança resta, então, uma conversão ao ser humano, que começa no momento do nascimento. O nascimento é o momento em que um ser (a criança) passa a pertencer a esse mundo, começando, portanto, a ser um de nós. Para Larrosa (2010, p. 187), pode-se dizer que "o recém-nascido não é outra coisa senão aquilo que nós colocamos nele" e quando uma criança nasce fica claro que, o que surge primeiramente é um "outro" entre nós - "outro", pois sempre estará além do que sabemos, do que queremos ou do que pensamos. "Não é o começo de um processo mais ou menos antecipável, mas uma origem absoluta, um verdadeiro início" (LARROSA, 2010, p. 187).

E o que podemos pensar sobre a relação entre nascimento e Educação? "A educação é o modo como as pessoas, as instituições e as sociedades respondem à chegada daqueles que nascem. A educação é a forma com que o mundo recebe os que nascem" (LARROSA, 2010, p. 188. [Grifo do autor]). O nascimento é uma novidade radical: o que não se espera, o que interrompe as nossas expectativas e o acontecimento imprevisto. Então, se o nascimento é a novidade, e a educação recebe essa novidade que é, ao mesmo tempo radical, podemos supor que tal relação é, em muitos momentos, dotada de conflitos.

Um conflito acontece pelo motivo de a instituição de Educação Infantil, seja ela creche ou préescola, ser pensada sob influências diversas, como a realidade social, política, histórica, econômica na qual está inserida. Outro, porém, buscou em sua característica dominadora e peculiar, uma forma de se inserir nesse contexto e de receber nossas crianças: o totalitarismo (LARROSA, 2010). O totalitarismo supõe a intenção de projetar, planificar, planejar o futuro de forma que haja continuidade naquilo que já está consolidado. Em outras palavras: o totalitarismo sempre foi avesso às novidades e leva a educação a reduzir a novidade da infância às condições pré-existentes, deduzindo-a a realidade já ajustada a uma ideia.

Essa realidade ajustada a uma determinada ideia variou conforme o contexto histórico. Por volta do final do século XIX, por exemplo, o Brasil vivia um momento político importante: a passagem de Império (disfarçado de governo regido por fazendeiros escravocratas, como preferem alguns) para a República. Dom Pedro II, imperador na época e responsável pela formalização do regime, serviu de árbitro político entre os que eram resistentes à ideia republicana e os grupos que defendiam a liberdade de expressão, sobretudo no contexto político. Dom Pedro II não foi considerado um absolutista, nem um 
político ousado como seu pai, Dom Pedro I, e embora com boas intenções, seu governo deixou como herança uma tradição de valorização das instituições e uma centralização em grupos políticos elitistas que se mantiveram limitados e fechados por muito tempo (CARVALHO, 1997).

O Brasil vivia, então, um momento de muitas discussões sobre como buscar a evolução para um país que, de colônia, queria se tornar um sinônimo de desenvolvimento para o mundo. Segundo Kuhlmann Júnior (1998) o conceito de civilização influenciou as principais ideias em todo o mundo, nesse momento. Entende-se por conceito de "civilização" a crença no progresso pela ciência e a mobilização entre várias nações para se adaptarem ao novo processo de produção. "Os países fizeram inventários de suas potencialidades e realizações, e as histórias sobre vários aspectos da vida social, escritas nesse período, anunciavam o trilhar da civilização para o progresso" (KUHLMANN JÚNIOR, 1998, p. 27).

Nesse contexto, um espírito de nacionalismo envolveu vários setores sociais num movimento além da Europa e dos Estados Unidos, chegando à América Latina e, consequentemente, ao Brasil. Em meio às várias correntes da época, como as transformações políticas, econômicas sociais e capitalistas, surgia também a preocupação com uma figura até então invisível: a criança, que deixa de ser objeto de interesse único da família e da igreja, e passa a ser alvo também das ações do Estado (RIZZINNI, 2011).

A criança, então, passou a representar o "futuro da nação", pois se fosse educada desde a Educação Infantil, seria muito útil a médio e longo prazo para os ideais republicanos. Era preciso, então, elaborar um plano de prevenção, recuperação e repressão, pois a criança era considerada um ser que precisava ser vigiado, educado, moldado e, se fosse o caso, recuperado, visto que a criança ameaçadora era assim vista por ser criada, muitas vezes, soltas, sem limites, conduzida pelas ruas e casas de detenções (RIZZINNI, 2011).

Segundo Kuhlmann Júnior (1998), a intencionalidade educativa começa a ter protagonismo a partir das discussões que buscavam colaborar para que o Brasil se tornasse "civilizado" - nesse momento, a infância passa a ser percebida, especialmente a partir de 1870, pelas esferas jurídicas, sanitárias e educacionais. $\mathrm{Na}$ esfera jurídica, a preocupação era com essa criança delinquente, de família pobre, que necessitava ser controlada e regenerada. Na esfera sanitária, a discussão era sobre como poderia se controlar a distribuição social na perspectiva da melhoria da raça do brasileiro e do cultivo do nacionalismo e, por fim, na esfera educacional, como esses espaços poderiam contribuir, por meio de várias ações para o alcance do disciplinamento moral, intelectual e corporal.

Para Rizzinni (2011), educar a criança pobre significava moldá-la para a submissão. Havia, nesse período, uma preocupação em educar o povo, pois as esferas econômicas mundiais naquele contexto exigiam outro tipo de preparo: a capacitação para um novo mercado de trabalho totalmente diferente daquele no qual o Brasil estava acostumado, desde sua colonização. Era preciso repensar uma educação que contemplasse os ideais capitalistas que estavam surgindo, aos poucos, nos horizontes brasileiros. Porém, a preocupação da elite letrada também era a de promover uma educação para civilizar sem, no entanto, abrir mão do controle e da vigilância que, antes se aplicavam às senzalas e agora se aplicariam a outros meios de trabalho. Vale a pena destacar que os pobres eram vistos como uma ameaça à elite burguesa e eles (os 
pobres) jamais poderiam desconfiar que juntos pudessem causar rebeliões, protestos e reivindicações sociais relevantes para uma equidade social no Brasil. A ideia era modernizar, mas manter o status quo.

Portanto, a infância passou a ser vista como um componente da ação civilizadora, nesse período, digna de preocupações e planejamentos futuros. As mudanças comportamentais a respeito das crianças, como por exemplo, os atos de violência física e moral, considerados comuns em determinadas épocas, são tomados como reprovação, pois a criança era o futuro na nação, um "vir a ser" que edificaria o nosso país.

Foi nesse contexto, segundo Kuhlmann Júnior (2010), que circularam muitas ideias novas sobre a infância por meio de encontros, simpósios e congressos internacionais nos quais a elite intelectual brasileira tentava se introduzir. Inicialmente, essa participação brasileira era marcada por relações pessoais ocorridas em viagens de intercâmbio e também pelas primeiras edições e traduções de publicações. Mais tarde, no último terço do século XIX, essas relações se ampliaram pelas associações e congressos de nível nacional e internacional, que difundiram tais propostas institucionais e pedagógicas.

No Brasil, um dos percussores de tais ideais considerados inovadores foi Rui Barbosa, que por volta da década de 1880 se deparou durante um desses congressos internacionais com os jardins de infância, idealizados por Fröebel, propagados pela Europa. Enquanto que, aqui no Brasil, a escola primária para a população brasileira, em geral, estava longe de ser uma realidade e esse quadro se agravava ainda mais quando o assunto era a Educação Infantil (KHULMANN JÚNIOR, 2010).

$\mathrm{Na}$ América Latina, as discussões começaram a se destacar a partir do século XX. Seguindo os exemplos dos congressos internacionais da época, foi realizado o $1^{\circ}$ Congresso Americano da Criança em Buenos Aires, em 1916. O segundo ocorreu em 1919 em Montevidéu e o terceiro, realizado no Rio de Janeiro em 1922, durante o Centenário da Independência organizado em conjunto com o $1^{\circ}$ Congresso Brasileiro de Proteção à Infância. Conforme Kuhlmann Júnior (2010), o período entre 1870 e 1920 foi o de pensar propostas e iniciativas que promovessem os debates sobre as relações com a infância e a organização educacional, que assume maior visibilidade com a formalização pelo Estado das instituições e associações que contribuiriam com essa formação da criança brasileira em diferentes esferas, como instâncias administrativas, políticas, educacionais, científicas, culturais, entre outras.

O Brasil estava cheio de problemas sociais e houve, nesse momento de alvorecer das ideias republicanas, uma união entre médicos, juristas e religiosos para que se pensasse como deveria ser a educação e a assistência às crianças brasileiras. No quesito "revolução educacional", o Estado de São Paulo saiu na frente e foi o pioneiro no Brasil no sentido de repensar a educação para a modernidade, tornando-se modelo para os demais Estados do Brasil, especialmente no período da Primeira República, que vai de 1889 a 1930.

Muitos dos ideais adotados nesse cenário corroboravam para a questão da infância como principal objeto de intervenção pedagógica. O movimento dos kindergartens (Jardins da Infância), divulgado por Fröebel na Europa, proclamava o papel protagonista da mulher na educação da infância - as mulheres eram chamadas a transcender seu papel materno, doméstico e privado para o contexto pedagógico e 
público. Família e educação pública seriam complementares na educação das crianças e não mais dicotômicas nesse processo (KUHLMANN JÚNIOR, 1998).

O primeiro Jardim de Infância público paulista foi o "Jardim de Infância Caetano de Campos", um anexo da Escola Normal, inaugurado em 18 de maio de 1896. Era um prédio novo, com quatro salas grandes e um salão central que tinha, nas paredes, retratos de Fröebel, Pestalozzi e Rousseau. Durante muito tempo, segundo Kuhlmann Júnior (1998), teve como clientela a elite paulistana, que tinha supostos privilégios e era favorecida nas matrículas.

A programação das atividades demonstrava uma preocupação com o controle e a vigilância das crianças, facilmente percebido pela própria divisão de horários: eram quatro horas de atendimento com previsão de vinte momentos diferentes de até quinze minutos cada. Aos sábados, as aulas tinham um horário mais livre, com exercícios orais de linguagem, jogos, cantos e passeios. De acordo com o "Guia das Jardineiras", o tempo recomendado para cada atividade era de 20 a 30 minutos, os jogos deveriam ser realizados sentados e alternados com os jogos de ação (aqueles em que as crianças imitariam o voo dos pássaros, a natação, o ato de semear e lavrar a terra etc.), com a ginástica e com os exercícios vocais (KUHLMANN JÚNIOR, 1998).

Conforme Kuhlmann Júnior (1998), as atividades nessas instituições públicas de Educação Infantil estavam marcadas por gestos e ações ritualizadas. A chegada e a saída eram realizadas com músicas, em filas, os gestos dos educadores, as formações corporais, a repetição, entre outros, eram exemplos de como isso ocorria. "É importante ter presente que, além dos momentos repetidos durante todos os dias pela rotina, as demais atividades desenvolvidas no jardim-de-infância apresentavam também um modo ritualístico de desenvolvimento" (KUHLMANN JÚNIOR, 1998, p. 130).

O que pretendemos, então, com esse breve histórico sobre a disciplinarização dos corpos, sobretudo por meio dos corpos infantis na Educação Infantil, é nos permitir a seguinte reflexão: por que, por mais de um século, tentamos moldar nossas crianças pelas instituições educacionais, entre elas, as instituições de Educação Infantil e por meio do corpo? Por que, até os dias atuais, percebemos uma privação do movimento, do jogo, da brincadeira, e outras significações que nos remetem ao "sujeito lúdico" nesses espaços? Por que não se permite evoluir no sentido de enxergar o lúdico como um importante aliado - pelo contrário, ainda pensamos na imposição de padrões de conduta através dos corpos das crianças?

Acreditamos que essa breve explanação histórica inicial nos transporta a uma reflexão: hoje, o que ocorre em muitas instituições de Educação Infantil, são frutos de escolhas feitas no passado. Não cabe a nós, nesse momento, julgar se tais decisões foram as mais acertadas ou não, se os motivos reais eram justificáveis ou não. Importa é pensarmos: até quando reagiremos, na Educação Infantil presente, com pensamentos pautados no século passado? 


\section{Direito de jogar e brincar: algumas reflexões sobre o que dizem alguns documentos para a infância no mundo}

Qual seria, então, alguns dos motivos para que a ludicidade, manifestada muitas vezes pelo jogo e pela brincadeira na Educação Infantil, seja discriminada e reprimida em alguns momentos? Pensando nisso, Vasconcelos (2006) parece ter uma resposta bastante relevante para a questão da privação do lúdico no contexto das instituições de Educação Infantil: o jogo não é considerado racional. Argumentando por meio de uma perspectiva histórica, o autor explica que a criação dos sistemas nacionais de educação a partir do século XIX, com ênfase na racionalidade técnica e instrucional, consolidou o brincar como pertencente à esfera do lazer e do passatempo infantil sendo associado, portanto, ao plano secundário de formação.

Assim, nesse modelo de educação instrucional, além de a concepção de indivíduo enxergar o homem como um ser passivo, não havia, nesse contexto, espaço para atividades que envolvessem jogos, brincadeiras e outras que estimulassem a construção de um sujeito ativo. "Ao contrário, na corrente passiva instrucional, não há lugar para brincadeiras" (VASCONCELOS, 2006, p. 62).

Além desses motivos, Vasconcelos (2006) ressalta que o jogo e a brincadeira estão também diretamente relacionados por essa concepção passiva instrucional, por serem concebidos como espontâneos, sentimentais, românticos e naturais, não estão, portanto, ligados à razão, considerada aqui como cerne para a promoção e exaltação do conhecimento científico, considerado o principal eixo de formação do ser humano

nessa concepção. É preciso, então, ousar brincar nas instituições de Educação Infantil, pois negar o universo lúdico das crianças é negar o trajeto de desenvolvimento humano. Criança que não brinca não é criança, e adulto que não brinca perdeu para sempre a criança que um dia existiu em seu íntimo.

Além de todas essas observações, negar o brincar à criança é não reconhecê-la como cidadã. Vale nesse momento lembrarmo-nos das palavras de Lima (2008): brincar e jogar são um direito das crianças, assegurado por vários documentos que se propõem a orientar a Educação Infantil. Em nosso país, podemos citar o exemplo da "Declaração Universal dos Direitos da Criança" (ORGANIZAÇÃO DAS NAÇÕES UNIDAS, 1959), a "Constituição Federal” (BRASIL, 1988), o "Estatuto da Criança e do Adolescente" ECA (BRASIL, 1990), o "Referencial Curricular Nacional para a Educação Infantil" - RCNEIs (BRASIL, 1998), os "Parâmetros Curriculares Nacionais" - PCNs (BRASIL, 1997) e, mais recentemente, as "Diretrizes Curriculares Nacionais para a Educação Infantil" (BRASIL, 2010) e as "Diretrizes Curriculares Nacionais da Educação Básica" (BRASIL, 2013) sendo esses dois últimos, considerados diretrizes obrigatórias a serem seguidas por todas as instituições de Educação Infantil no Brasil.

Apesar de tais documentos serem vistos como algo positivo por alguns em termos de, pelo menos, tentar assegurar o direito de brincar e jogar das crianças é preciso lembrar que, quando são necessárias tantas discussões, em vários âmbitos, para que se assegure algum direito, isso pode significar que os mesmos não estão sendo garantidos da forma como deveriam. Nesse sentido, Lima (2008) ainda reflete que, como agravante das privações desses direitos, é visível uma pressa pelo processo de escolarização, especialmente na Educação Infantil, em que as crianças já nessa faixa etária são expostas a uma sobrecarga de trabalho, fazendo com que tenham cada vez menos tempo para as práticas lúdicas. O 
autor ainda nos lembra de que em outros tempos, por volta do século XVIII, as práticas lúdicas eram compartilhadas entre adultos e crianças, o que promovia uma troca maior de experiências entre ambos. Obviamente, os dias atuais são bem diferentes e não se trata aqui de propormos uma mudança radical nas atividades dos adultos, porém, precisamos reconhecer que atualmente, as crianças sofrem muito mais com essa negação das práticas lúdicas.

Não estamos propondo a "infantilização do adulto" ou que a única atividade essencial na formação da criança seja o jogo ou a brincadeira, mas sim, que esses espaços de expressão e incorporação da cultura e de valores precisam ser respeitados e valorizados, e que conhecimentos, condições temporais, espaciais e materiais adequados garantam à criança o direito à infância e ao brincar (LIMA, 2008, p. 30 - 31).

Ou seja, mesmo com tantos pressupostos teóricos e com tantos documentos que tentam assegurar o direito das crianças de brincar e jogar, este vem sendo constantemente negligenciado às crianças. Partindo diretamente para a questão do jogo e da brincadeira nos referidos documentos, estabelecendo uma ordem cronológica, destacaremos textos que tornam as reivindicações do brincar e jogar nas instituições de Educação Infantil, percebidas e legitimadas pelas falas das crianças.

Começaremos pela Declaração Universal dos Direitos das Crianças (ORGANIZAÇÃO DAS NAÇÕES UNIDAS, 1959), que ao se referir ao direito à educação gratuita e ao lazer infantil, propõe em seu Princípio IV: "A criança deve desfrutar plenamente de jogos e brincadeiras os quais deverão estar dirigidos para a educação; a sociedade e as autoridades públicas se esforçarão para promover o exercício deste direito".

O referido documento, conforme Júnior e Ferreira (S/D) foi inspirado na "Carta das Nações Unidas" de 1945 que objetivava garantir os direitos diversos das crianças pelo mundo, especialmente após o fim das $1^{\mathrm{a}}$ e $2^{\mathrm{a}}$ Guerras Mundiais, que vitimou milhões de pessoas, especialmente crianças. Além disso, após o fim do caos proporcionado por esses dois eventos, muitas crianças perderam seus pais e se tornaram vulneráveis em todo o mundo. A "Declaração Universal dos Direitos da Criança” (ORGANIZAÇÃO DAS NAÇÕES UNIDAS, 1959) procurou então incentivar os países membros da Organização das Nações Unidas - ONU, a garantir os direitos das crianças, como crescer em um ambiente familiar em contato com o amor, a compreensão e a felicidade, favorecendo assim o desenvolvimento de sua personalidade com intuito de propor uma vida individual e em sociedade ambientadas no espírito de liberdade, igualdade e solidariedade.

Esse documento acabou por nortear muitos outros que visavam à garantia dos direitos das crianças pelo mundo. No Brasil, por exemplo, inspirou entre outros o Decreto $\mathrm{n}^{\circ} 99.710$ de 21 de Novembro de 1990, que aprovava oficialmente a partir dali a "Convenção dos Direitos da Criança" como um dos norteadores para o respeito dos direitos da criança em nosso país, visto que a própria Constituição Federal brasileira, promulgada em 1988 (BRASIL, 1988), já elencava como dever do Estado uma Educação Básica obrigatória e gratuita.

Em seguida, podemos citar a elaboração do "Estatuto da Criança e do Adolescente - ECA" (BRASIL, 1990), que em seu Capítulo II, que trata do Direito à Liberdade ao Respeito e à Dignidade, propõe:

Art. 15.A criança e o adolescente têm direito à liberdade, ao respeito e à dignidade como pessoas humanas em processo de desenvolvimento e como sujeitos de direitos civis, humanos e sociais garantidos na Constituição e nas leis.

Art. 16.O direito à liberdade compreende os seguintes aspectos: 
I - ir, vir e estar nos logradouros públicos e espaços comunitários, ressalvadas as restrições legais;

II - opinião e expressão;

III - crença e culto religioso;

IV - brincar, praticar esportes e divertir-se;

$\mathrm{V}$ - participar da vida familiar e comunitária, sem discriminação;

VI - participar da vida política, na forma da lei;

VII - buscar refúgio, auxílio e orientação (BRASIL, 1990).

Interessante observarmos que o direito de brincar, praticar esportes e se divertir esteja ligado diretamente ao Artigo 16 que preza, em sua redação, o direito à liberdade - palavra cujo em seu sentido literal as crianças têm sido muito privadas nos últimos tempos e que geram muitas queixas quando essas estão em muitos ambientes educacionais, entre eles, as instituições de Educação Infantil.

Dando sequência às discussões sobre os documentos que tratam da Educação das crianças, falaremos a partir de agora sobre a atual "Lei de Diretrizes e Bases da Educação Nacional" - LDBEN (BRASIL, 1996), e começaremos por destacar que na época havia uma grande expectativa em torno de sua implantação, tanto que segundo Saviani (2007) sua própria regulamentação já andava a todo vapor enquanto que sua aprovação sequer havia sido concluída. O país passava por muitas transformações e na área da Educação muitos paradigmas estavam sendo debatidos - a nova Lei, entendida como a maior da educação do país, abaixo apenas da Constituição Federal, gerava a esperança de que muitos dispositivos educacionais que precisavam ser regulamentados por uma legislação específica enfim ocorressem (SAVIANI, 2007).

É certo que tal regulamentação ocorreu de fato, com relação aos muitos setores do ensino público brasileiro, e em outros nem tanto, mas nos atentaremos à questão do direito de brincar e jogar, desde a Educação Infantil, dentro desta Lei, já lembrados pelos outros documentos citados por esse estudo e que, portanto, eram referências no que se refere a esse assunto.

A maior comparação que podemos fazer com relação às duas Leis - a de no 5.692/71 e a de $n^{\circ}$ 9.394/96 - está relacionada diretamente à visão que se tinha das possibilidades das práticas lúdicas desde a Educação Infantil. No caso da Lei anterior, qualquer prática de movimentos previstos dentro das instituições educacionais se dava por meio das aulas de Educação Física que, previstas em seu Artigo $7^{\circ}$, eram obrigatórias e deveriam estar incluídas no currículo dos ensinos de $1^{\circ}$ e $2^{\circ}$ graus.

$\mathrm{Na}$ LDBEN em vigor hoje - a Lei no 9.394/96 -, a referência às práticas de movimento não menciona em nenhum momento de forma direta o direito de brincar e jogar nas instituições educacionais (o que também era perceptível na Lei anterior). Uma das tentativas de debater, refletir e tentar realizar uma nova prática pedagógica nesse sentido e que contemplasse toda a Educação brasileira, de forma geral, foi pensar em diretrizes pedagógicas pautadas em novas ideias e em novos referenciais teóricos até então para a realidade brasileira.

Começou então nesse momento a elaboração de dois documentos que podemos considerar muito importantes historicamente: Os "Parâmetros Curriculares Nacionais" - PCNs (BRASIL, 1997) destinado ao Ensino Fundamental e os "Referenciais Curriculares Nacionais para a Educação Infantil" RCNEIs (BRASIL, 1998) destinado à Educação Infantil. Nos atentaremos mais a esse último documento, por estar mais diretamente relacionado à nossa discussão. 
Sobre os "Referenciais Curriculares Nacionais para a Educação Infantil" - RCNEIS (BRASIL, 1998), queremos afirmar que, mesmo com toda a importância histórica que esse documento possui, no sentido de propor uma discussão sobre as especificidades da Educação Infantil brasileira, segundo Cerisara (2002), sua versão final não considerou muitas das discussões que haviam sido feitas sobre a Educação Infantil naquele momento, como as realizadas pelo grupo coordenado pela professora Angela Barreto na "Coordenação Geral de Educação Infantil” - COEDI, no período entre 1994 a 1998, que tinha como proposta construir uma "Política Nacional para a Educação Infantil” naquela época.

Além disso, alguns debates realizados pelo "GT-07 - Educação da Criança de 0 a 6 anos" da “Associação Nacional de Pós-graduação e Pesquisa em Educação" - ANPED, em sua XXI reunião, por exemplo, debateu a versão preliminar dos RCNEIs resultando num parecer técnico que não foi considerado pela versão final.

\begin{abstract}
Em outubro de 1998 a versão final do RCNEI foi divulgada sem que os apelos dos pareceristas por mais tempo para debates e discussões fossem atendidos. Outro aspecto que merece destaque é que o RCNEI atropelou também as orientações do próprio MEC, uma vez que foi publicado antes mesmo que as Diretrizes Curriculares Nacionais, estas sim mandatórias, fossem aprovadas pelo Conselho Nacional de Educação (CERISARA, 2002, p. 336).
\end{abstract}

Ainda, segundo Cerisara (2002), a própria forma como os RCNEIs (BRASIL, 1997) estão organizados, contempla muito mais uma Educação com características do Ensino Fundamental do que da Educação Infantil: subdivididos por Eixos, com objetivos, conteúdos, orientações didáticas, orientações gerais para o professor e bibliografia, promovendo assim mais uma "didatização" do processo de identidade e da ampliação da autonomia, entre outros, do que considerar de forma mais específica, as necessidades da criança na Educação Infantil.

Assim, promove-se, pelos RCNEIs (BRASIL, 1998) uma concepção educacional diferente das discutidas pela COEDI e pela ANPED naquela época (que contemplava propostas simples e diretas, como critérios de organização e funcionamento das creches, além de práticas pedagógicas adotadas no trabalho com as crianças partindo dos direitos da criança) e que condizia mais com a visão neoliberal da Educação e subordinada ao Ensino Fundamental (CERISARA, 2002).

Já em 2010, surgem as "Diretrizes Curriculares Nacionais para a Educação Infantil” - DCNEIs (BRASIL, 2010). O documento expõe que a prática pedagógica nos espaços de Educação Infantil deve contribuir para o desenvolvimento de aspectos sociopolíticos, que implica oferecer recursos humanos para exercer seus direitos sociais, entre eles o de brincar (BRASIL, 2010).

A proposta pedagógica das instituições de Educação Infantil deve ter como objetivo garantir à criança acesso a processos de apropriação, renovação e articulação de conhecimentos e aprendizagens de diferentes linguagens, assim como o direito à proteção, à saúde, à liberdade, à confiança, ao respeito, à dignidade, à brincadeira, à convivência e à interação com outras crianças (BRASIL, 2010, p. 18).

Para que tais objetivos sejam atingidos, o documento dá algumas orientações e faz observações importantes sobre a organização do espaço pedagógico que deve prover uma ampliação do conhecimento de mundo das crianças. Com relação ao movimento corporal, tão importante para as crianças nesta fase, o documento é claro em afirmar que o espaço das instituições de Educação Infantil deve facilitar o 
deslocamento das crianças de forma a promover a interação entre elas, além de possibilitar o acesso a materiais diversos. Entende-se como "acesso a materiais diversos", por exemplo, a oferta de brinquedos e outros equipamentos que propiciem o brincar, respeitando as caraterísticas ambientais e socioculturais da comunidade em questão (BRASIL, 2010).

Ainda sobre os DCNEIs (BRASIL, 2010), vale lembrar que sua proposta curricular compõe dois eixos centrais - as interações e as brincadeiras. Para isso, é preciso que as crianças tenham garantidas pelas instituições e pelos professores a oportunidade de ampliar suas experiências sensoriais, expressivas e corporais. Já o Ensino Fundamental teve sua proposta atualizada pelas "Diretrizes Curriculares Nacionais da Educação Básica" (BRASIL, 2013). O documento reconhece que a brincadeira é uma atividade importante desde a Educação Infantil e no Ensino Fundamental e menciona que os conteúdos que compõem sua base nacional comum têm origem em várias áreas, entre elas as atividades desportivas e corporais. O currículo de base nacional comum deve observar o artigo 26 da Lei no 9.394/96 - LDBEN que inclui a Educação Física como área do conhecimento e, portanto, disciplina obrigatória na educação brasileira.

É preciso, entretanto, lembrar que grande parte desses documentos foi pensada, organizada e divulgada com a influência de organismos multilaterais, como o Banco Mundial - BM, a Organização para a Cooperação e o Desenvolvimento Econômico - OCDE, a Organização Mundial de Comércio - OMC, e a própria Organização das Nações Unidas para a Educação, Ciência e Cultura - UNESCO. Isso significa nas palavras de Mota Júnior e Maués (2014) entender tais documentos com grande influência neoliberal em várias áreas, incluindo a da Educação.

Segundo Mota Júnior e Maués (2014), a partir da década de 1970 a Educação ganhou mais visibilidade perante esses organismos, pois era entendida por muitos como uma ferramenta funcional a serviço da expansão do capitalismo, ou seja, pela Educação havia uma grande oportunidade de se formar uma nova geração de trabalhadores que pudessem ser úteis às novas exigências capitalistas do mundo.

Tais organismos passaram, então, a investir na Educação: lançaram padrões a serem seguidos pelas instituições educacionais dos países em desenvolvimento; promoveram fundos de investimentos que incentivaram a descentralização da gestão e a centralização das avaliações que, por sua vez, tornaram-se cada vez mais pautadas em resultados e fixações de metas de desempenho; incentivaram a formação docente como eminentemente prática por meio de cursos de treinamento; inseriram padrões nos quais a educação é analisada por critérios mercadológicos; passaram a conferir a qualidade da educação, pautada por medições de resultados; elaboraram um currículo que é resumido a conteúdos; aplicaram propostas pedagógicas generalizadoras; priorizaram a capacitação em serviço, deixando a formação inicial em segundo plano; dentre outros aspectos. (TORRES, 2000; ALTMANN, 2002; MOTA JUNIOR; MAUÉS, 2014).

Isso implica entender que esses mesmos organismos que garantem às crianças o direito de brincar, de jogar, de participar de um lazer e de ter condições dignas de viver a infância por meio de muitos documentos e Leis, também exigem de instituições diretamente ligadas a elas algumas ações para que a Educação caminhe conforme seus preceitos e objetivos, que diretamente sofre influências diversas advindas das condições impostas e exigidas por esses mesmos órgãos. 
Nesse sentido, Mota Junior e Maués (2014) são categóricos em afirmar que o Banco Mundial, por exemplo, se tornou um Ministério da Educação à parte dos países periféricos - entre eles, o Brasil -, e é ele quem dita muitas das ações a serem adotadas na Educação, pois sua capacidade de emprestar recursos o tornou o centro mundial de desenvolvimento a ser seguido pelos emergentes. No caso específico do Brasil, a partir do governo de Fernando Collor de Melo (1990 - 1992), essas ações norteadas pelo Banco Mundial significaram

[...] a radicalização da libertação da economia, com as privatizações dela decorrentes, e a destruição de um precário Estado Social por meio de uma contrarreforma do Estado, cujos efeitos mais visíveis sobre a educação básica e superior são o avanço do setor privado, a precarização do público e a penetração dos mecanismos e valores de mercado sobre a gestão, o financiamento, a avaliação e a produção de conhecimento (MOTA JÚNIOR; MAUÉS, 2014, p. 1142).

Portanto, não podemos nos esquecer de que, ao mesmo tempo em que a criança tem vários direitos, entre eles o da vivência do lúdico em contextos educacionais, as instituições de Educação Infantil também são pressionadas numa lógica neoliberal que visa uma ascensão social por meio da educação e que se limita a padrões que atendem à economia e à estabilidade política, sustentada por muitos organismos multilaterais. Trata-se de uma perspectiva em que a Educação deve ser pautada na ideia de que o capital humano (quantidade ou grau de educação e de qualificação tomado como indicativo de um volume de conhecimentos) é essencial para a potencialização da capacidade de produção (MOTA JÚNIOR; MAUÉS, 2014).

Para Altmann (2002), tais medidas apenas reforçam a má qualidade da educação além de contribuir para a permanência da desigualdade no sistema educacional. Em uma engrenagem em que a prioridade é dada apenas à Educação Básica, trazendo uma mensagem sutil de que essa modalidade de ensino basta para que todos tenham a garantia de oportunidades iguais no mercado de trabalho e na vida, pensar na Educação como ascensão social e econômica é pura ilusão - está sim, incentivando que tudo permaneça como está, inclusive o status em que cada um se encontra na sociedade.

O fato, é que nossas crianças estão expostas a todos esses fatores, que vão desde políticos, econômicos, sociais, culturais e até materiais. Porém, nenhum deles, em nossa opinião, justifica a ausência cada vez mais acentuada do lúdico na infância. Entretanto, antes de partirmos para nossas conclusões, pensamos ser viável discutir a importância do brincar no contexto da Educação Infantil, sem que esse esteja obrigatoriamente associado a cumprir apenas objetivos pedagógicos em si.

Primeiramente, é preciso reconhecer que o brincar é um componente da formação humana e importante para os processos de desenvolvimento e aprendizagem, não apenas para as crianças. Segundo Borba (2007), nós, adultos, é que elegemos o brincar como um "tempo perdido" e como uma atividade caracterizada como oposta ao trabalho. Isso, por si só, já vincula o brincar a processos considerados “não produtivos" e que não geram, portanto, resultados.

A brincadeira, então, fica reduzida apenas a momentos em que o objetivo é o de "relaxar" ou "repor as energias para o trabalho". Pensar a brincadeira como uma ação que não é oposta ao trabalho e que se articula a muitos processos de aprendizagem e desenvolvimento infantil é um dos principais caminhos a seguir (BORBA, 2007). 
O brincar é um fenômeno cultural e compõe um dos pilares das Culturas Infantis. Nesse sentido, para Sarmento (2004) a ludicidade está diretamente ligada às ações do brincar que por sua vez constitui-se como um dos primeiros elementos que favorecem o aparecimento das Culturas Infantis. Para o autor, o brincar "é a condição da aprendizagem e, desde logo, da aprendizagem da sociabilidade" (SARMENTO, 2004, p. 16). Porém, em muitos contextos educacionais o brincar não é visto com essa propriedade.

O que vemos na maioria de nossas instituições de ensino são rotinas muito parecidas com as descritas por Milstein e Mendes (2010): a exigência de que as crianças fiquem sentadas, enfileiradas e imóveis durante todo o tempo de aula, a proibição das conversas entre as crianças, a obrigação de se cumprir o tempo determinado para tarefas básicas como beber água e ir ao banheiro, não gritar, não bagunçar ou correr mesmo durante o intervalo, etc.

Brincar é uma experiência cultural que envolve muitos processos, como a interação e a reflexão envolvendo a construção de habilidades, além de conhecimentos e valores sobre o mundo (BORBA, 2007). O problema parece ser preocupante quando esse brincar está sugerido, em muitas propostas pedagógicas, apenas como um pretexto para o ensino de conteúdos e quando essa visão limitada do brincar (reconhecido somente como recurso para se alcançar a aprendizagem de um conteúdo específico) se estabelece, corremos o risco de "didatizar" o brincar: essa ação passa de uma configuração livre e espontânea, para uma caraterística sistematizada de ensino para a aprendizagem de conteúdos. Parafraseando Huizinga (1971), se esse brincar ou jogar se sujeitar a ordens, deixa de ser livre e passa a ser, no máximo, uma imitação forçada ou uma tarefa a cumprir.

Que possamos optar pela presença do brincar e jogar no cotidiano de nossas instituições de Educação Infantil independente das pressões políticas e econômicas, das tradições históricas, das condições sociais, das crenças individuais e de inúmeros outros fatores que porventura quiserem nos convencer do contrário, amparados em concepções que respeitem a criança e seus direitos.

\section{Considerações finais}

São muitos os argumentos para a privação do lúdico no contexto das instituições de Educação Infantil, entre outros, destacamos: a visão de que as questões relacionadas ao corpo são secundárias e conteúdos considerados "menos importantes" ou, que o corpo disciplinado (imóvel, quieto, em silêncio) é um corpo que aprende mais e melhor ou, ainda, que o jogo e a brincadeira atrapalham a aprendizagem e descontrolam o ambiente, etc.

Independente do motivo para que esses argumentos ainda permaneçam em nossas instituições de Educação Infantil, sejam de ordem histórica, por comodismo, pela formação deficitária, pela falta de tempo, pelo fato de haver pouco espaço no currículo para as práticas lúdicas, pelo pouco investimento financeiro, pelo mínimo de reconhecimento do jogo e da brincadeira como importantes, pela ausência de políticas públicas que reconheçam as especificidades da ludicidade, etc., precisamos refletir e mudar algumas de nossas concepções pedagógicas a respeito dessa temática na Educação. 
Pensar a criança hoje, como um ator social, como uma categoria geracional que tem suas particularidades, é pensar na criança como um ser que quer brincar, jogar, ter experiências lúdicas fora do ambiente educacional formal, mas, principalmente, ela quer vivenciar isso também dentro dele. A instituição de Educação Infantil, como espaço promotor da ordem e do controle, não permite, em muitos momentos, que tais vivências ocorram. Não estamos nesse momento afirmando que nesse ambiente não precisa ter ordem de nenhum tipo. A questão a ser discutida parece ser em como tais ordens se estabelecem ainda hoje no contexto educacional.

É preciso ressaltar que o jogar e o brincar são reconhecidos como direitos das crianças por vários documentos no âmbito nacional e internacional. Porém, como bem nos lembra Lima (2008), o fato de existir esses textos que tentem assegurar esses direitos, isso implica entender que os mesmos estão sendo negligenciados de alguma maneira. Caminhando nesse sentido, propomos a seguinte reflexão: se existem tais discussões que apontam as atividades lúdicas como direito das crianças, precisamos fazer valer tal direito, independente de existirem pressões políticas, pedagógicas, e por aumento de índices, como já vimos. Primeiro porque não há, então, nenhum impedimento para que nós, professores, empreguemos a ludicidade em nossa prática educativa - pelo contrário: as práticas lúdicas são tomadas como indispensáveis pelas diretrizes educacionais brasileiras e precisam adentrar nas instituições educacionais ou qualquer outro ambiente frequentado pelas crianças.

Segundo, pois se reclamamos, em nosso dia-a-dia, que a Educação precisa quebrar paradigmas antigos e superar atitudes pautadas em valores "tradicionais" de nossa prática pedagógica para que ela se transforme, podemos sim começar pela garantia da brincadeira e do jogo. Se existem direitos que não estão assegurados na prática educativa por vários motivos como a burocracia, a falta de recursos etc., esses, porém, dependem muito mais de nós, professores e gestores d Educação Infantil, do que de qualquer outra engrenagem do sistema.

Cabe, então, ao professor garantir um ambiente capaz de aguçar a curiosidade das crianças pelo conhecimento e diversificar os seus conteúdos. Propomos, então, que isso seja feito com diálogo, com mais participação infantil nas tomadas de decisões e com mais conhecimento dos professores sobre as culturas infantis.

Infelizmente, ainda hoje, presenciamos muito o furto do lúdico nas instituições de Educação Infantil. As crianças inseridas atualmente em nosso sistema educacional estão a todo instante nos revelando como são rigorosas as privações do jogo e da brincadeira nesse contexto e, ainda, com relação às reflexões sobre os possíveis motivos nos quais essas proibições continuam ocorrendo, buscamos, por meio das discussões expostas, refletir sobre alguns deles.

Mas, não podemos deixar de inferir que, independente da época, do contexto, da política vigente e da proibição das manifestações lúdicas infantis pelos adultos, ao longo da história, as crianças sempre encontram meios de continuar sendo crianças, manifestados por meio de práticas lúdicas que não podemos interferir, como o caso "fictício" da "menina que aprendeu a voar" ("fictício" entre aspas, pois sabemos que apesar de se tratar de uma história inventada, como frisada no início, acontece com muita 
frequência em várias instituições escolares) e que serviu de ilustração para iniciarmos nossa discussão sobre a realidade de muitas instituições de Educação Infantil, ainda, hoje.

Saindo da ficção para a vida real, podemos afirmar que em nosso cotidiano, mesmo utilizando de diversos mecanismos que tentam, em vão, abolir o lúdico, ele sempre existirá nos sonhos e nas ações da maioria das crianças.

Lúcia começou a olhar pela janela e as nuvens passavam, tão brancas, e o céu era tão aqul, e em algum lugar do mundo as ondas do mar batiam na praia e levantavam espuma, e no parque tinha rodagigante e montanha-russa.

E na esquina tinha o pipoqueiro e o bomem que vendia algodão-doce e tinha um gordo que vinha pela rua assobiando uma música tão bonita e Lúcia se distraiu e soltou os pés da carteira e começon a subir, a subir...

E quando Lúcia olbou, viu que a Tábata também estava voando, e o Zé Bento também, e o Cassiano, a Denise, o Davi, o Pedro, a Juliana... (...) Tinha crianças gordas e magras, altas e pequeninas, louras, mulatas e morenas, tinha crianças inteligentes e burras, e voavam todas, rindo-se muito, alegres pelo céu.

Só uma ou outra criança não conseguiu voar e ficou tristinha, sentada na classe.

Dona Isolda chegou à janela, olhou para o alto e chorou uma lágrima salgada (Ruth Rocha - A menina que aprendeu a voar).

Independente de permitirmos ou não, de proibirmos ou não, as crianças continuarão a brincar nem que seja em um local em que os adultos não podem entrar; claro, a não ser que as próprias crianças os convidem: dentro da cabecinha delas, pela imaginação, em seus sonhos. Que tal nos lembrarmos da nossa infância e reconhece-la, participando junto com as crianças desses momentos indispensáveis para as suas vidas?

\section{Referências}

ALTMANN, H. Influências do Banco Mundial mo projeto educacional brasileiro. Educação e Pesquisa, São Paulo, v.28, n.1, p. 77 - 89, Jan./Jun. 2002.

AZEVEDO, N. C. S. Culturas Lúdicas infantis na escola: entre a proibição e a criação. 2016. 266 f. Tese (Doutorado em Educação). Universidade Estadual Paulista “Júlio de Mesquita Filho”, UNESP, Presidente Prudente.

BRASIL. Presidência da República. Casa Civil. Subchefia para Assuntos Jurídicos. Lei no $\mathbf{5} .692$ de 11 de Agosto de 1971. Fixa Diretrizes e Bases para o Ensino de $1^{\circ}$ e $2^{\circ}$ graus e dá outras providências. Brasília, 1971.

BRASIL. Câmara dos Deputados. Diretoria Legislativa. Centro de Documentação e Informação. Coordenação Edições Câmara. Constituição da República Federativa do Brasil. Brasília, 1988.

BRASIL. Presidência da República. Casa Civil. Subchefia de Assuntos Jurídicos. Lei $\mathbf{n}^{\mathbf{0}} 8.069$ de 13 de Julho de 1990. Dispõe sobre o Estatuto da Criança e do Adolescente e dá outras providências. Brasília, 1990.

BRASIL. Ministério da Educação e do Desporto. Lei no 9.394 de 20 de Dezembro de 1996. Estabelece as Diretrizes e Bases da Educação Nacional. Brasília, 1996. 
BRASIL. Ministério da Educação e do Desporto. Secretaria de Educação Fundamental. Introdução aos Parâmetros Curriculares Nacionais. v. 1. Brasília, 1997, 79 p.

BRASIL. Ministério da Educação e do Desporto. Secretaria de Educação Fundamental. Departamento de Políticas da Educação Fundamental. Referenciais Curriculares Nacionais para a Educação Infantil. v. 1. Brasília, 1998, 101 p.

BRASIL. Ministério da Educação. Secretaria de Educação Básica. Diretrizes Curriculares Nacionais para a Educação Infantil. Brasília, 2010, 36p.

BRASIL. Ministério da Educação. Secretaria de Educação Básica. Secretaria de Educação Continuada, Alfabetização, Diversidade e Inclusão. Secretaria de Educação Profissional e Tecnológica. Conselho Nacional de Educação. Câmara Nacional de Educação. Diretrizes Nacionais Curriculares da Educação Básica. Brasília, 2013, 565 p.

BORBA, A. M. O brincar como um modo de ser e estar no mundo. In: BRASIL. Ministério da Educação. Secretaria de Educação Básica. Ensino Fundamental de Nove anos: orientações gerais para a inclusão da criança de seis anos de idade. Brasília: MEC/ SEB, 2007, p. 33 - 46.

CERISARA, A. B. O Referencial Curricular Nacional para a Educação Infantil no contexto das Reformas. Educação e Sociedade, Campinas, v. 23, n. 80, p. 326 - 345, Set./ 2002.

FREIRE, J. B. De corpo e alma. O discurso da motricidade. São Paulo: Summus, 1991, 153 p.

Da criança, do brinquedo e do esporte. Motrivivência, Jun. 1993, p. 22 - 29.

Uma pedagogia lúdica. In: ARANTES, V. A. (Org.). Humor e alegria na educação. São Paulo: Summus, 2006, p. $127-149$.

GONÇALVES, M. A. S. Sentir, pensar, agir. Corporeidade e educação. Campinas: Papirus, 2001, 197 p.

HUIZINGA, J. Homo ludens:o jogo como elemento da cultura. 2.ed. São Paulo: Perspectiva, 1971. 243p.

JUNIOR, V. H. A.; FERREIRA, P. R. V. Convenção sobre os direitos da criança e do Adolescente. Disponível em: http://www.pge.sp.gov.br/centrodeestudos/bibliotecavirtual/direitos/tratado11.htm. Acesso em: 05/09/2016. 
KUHLMANN JÚNIOR, M. Infância e educação infantil. Uma abordagem histórica. Porto Alegre: Mediação, 1998, 210 p.

LARROSA, J. O enigma da infância. In: LARROSA, J. Pedagogia profana. Danças, piruetas e mascaradas. Belo Horizonte: Autêntica, 2010, p. 183 - 198.

LIMA, J. M. O jogo como recurso pedagógico no contexto educacional. São Paulo: Cultura Acadêmica, 2008, 157 p.

MOTA JUNIOR, W. P.; MAUÉS, O. C. O banco Mundial e as políticas educacionais brasileiras. Educação \& Realidade, Porto Alegre, v.39, n.4, p. 1137 - 1152, Out./ Dez. 2014.

ORGANIZAÇÃO DAS NAÇÕES UNIDAS. Assembleia das Nações Unidas. Declaração Universal dos Direitos da Criança. 1959.

RIZZINNI, I. O século perdido. Raízes históricas das políticas públicas para a infância no Brasil. São Paulo: Cortez, 2011, 199 p.

ROCHA, R. A menina que aprendeu a voar. São Paulo: Moderna, 2012, 32 p.

SAVIANI, D. Da nova LDB ao FUNDEB. Campinas, Autores Associados, 2007, 310 p.

SÃO PAULO. Regimento interno das escolas públicas do Estado de São Paulo. Decreto no 248 de 26 de julho de 1894. Aprova o regimento interno das escolas públicas. São Paulo, 1891.

TORRES, R. M. Melhorar a qualidade da educação básica? As estratégias do Banco Mundial. In: TOMMASI, L.; WARDE, M. J.; HADDAD, S. O Banco Mundial e as políticas educacionais. São Paulo: Cortez, 2000, p. $125-193$.

VASCONCELOS, M. S. Ousar Brincar. In: ARANTES, V. A. (Org.). Humor e alegria na educação. São Paulo: Summus, 2006, p. 57 - 74 . 